\title{
Reproduction of Tables: Are Some Publishers Ignoring Fair Use/Dealing?
}

\author{
Shashi S. Seshia
}

Can. J. Neurol. Sci. 2010; 37: 914-916

In the not-so-distant past, when authors wished to reproduce tables or figures from another publication, one wrote to the authors of that publication with a polite request. There was a prompt and gracious response. The goals of science and knowledge were served at no cost, while the reproduction drew attention to the contributions of the original authors.

Now, one has to seek permission from the publisher through a byzantine impersonal user-unfriendly electronic process. A fee may have to be paid before approval is granted. As the following examples illustrate, some publishing houses may not only be disregarding fair use/dealing concepts of copyright laws but also ignoring the sentiments of the authors who have transferred copyright to them.

\section{EXAMPLES}

I first encountered the 'new' culture about two years ago when I wanted to reproduce a figure from a journal publication for a manuscript from which I gained no financial benefit. I was advised that the cost to do so would be US\$300.00. The authors of the publication were outraged when I informed them; it transpired that their educational institution held the copyrights, not the publishers, and they granted me permission without charge. In a recent example, a different publishing house (Wolters Kluwer Health Medical Research: WKHMR) quoted a fee of US\$97.75 to reproduce a table from an article in a journal, Current Opinion in Neurology, published by them. The table itself could be considered derivative from an earlier publication. When I informed the distinguished authors of the table (who had given their permission earlier but asked me to also seek permission from the publisher) about the charge, one of them wrote to the journal/publisher concerned, strongly opposing the fee: "I am really at a loss to understand why you have chosen to do this. There is every reason to allow this reproduction and no reason to stop it. The author has honestly asked to reproduce a single table; frankly, it is unacceptable to charge for that, and [you] should reverse this decision immediately. You should be proud and pleased that articles are cited for years...Please reconsider." Unfortunately, the Permissions Editor of WKHMR vetoed the request, writing back "The author cannot waive the fees. The author gave us the rights to the article and we publish the journal." The contemptuous disregard of the request of the authors of the article should concern everyone involved in the pursuit and dissemination of knowledge, authors included. My co-authors and I elected not to reproduce the table; discussion with colleagues suggests they have had similar experiences, prompting this commentary. In contrast, at about the same time, Wiley-Blackwell, publishers of the journal Headache, granted permission without charge, to reproduce, what to my knowledge, is the first table summarizing a proposed classification for chronic daily headache.

\section{Discussion}

Copyright laws, especially in this digital electronic age, cover a wide range of areas. None disputes laws that protect the moral, intellectual and financial rights of individuals or corporations on issues such as plagiarism, illegally copying or reproducing published or recorded work for financial gain. Discussion is confined to what is common place in (scientific) literature: reproducing a table or figure or quoting specific lines from a previous publication i.e., a small amount of material relative to the whole, acknowledging the source and done without financial gain as a motive. To my knowledge, these have not been specifically addressed in any legal document but the principles are covered under 'Fair Use' and 'Fair Dealing' concepts of copyright laws.

\section{Copyright Act in the United States ${ }^{1}$}

Section 107 (page 19) of the Copyright Act allows for "some" copying and distribution without permission of the copyright holder or payment. In order to avoid error through paraphrasing, the relevant paragraph is quoted verbatim from the Act $^{1}$ :

"The fair use of a copyrighted work, including such use by reproduction in copies or phonorecords or by any other means specified by that section [sic], for purposes such as criticism, comment, news reporting, teaching (including multiple copies for classroom use), scholarship or research, is not an infringement of copyright (italics mine). In determining whether the use made of a work in any particular case is a fair use the factors to be considered shall include-(1) the purpose and character of the use, including whether such use is of a commercial nature or is for nonprofit educational purposes; (2) the nature of the copyrighted work; (3) the amount and substantiality of the portion used in relation to the copyrighted work as a whole; and (4) the effect of the use upon the potential

From the Department of Pediatrics, Division of Pediatric Neurology, University of Saskatchewan, Saskatoon, Saskatchewan, Canada.

Received January 14, 2010. Final Revisions Submitted May 8, 2010.

Correspondence to: Shashi S. Seshia, Department of Pediatrics, Division of Pediatric Neurology, University of Saskatchewan, Saskatoon, Saskatchewan, S7N 0W8,Canada. 
market for or value of the copyrighted work."1 These four elements admittedly open to subjective interpretation as many laws are, constitute the basis for the 'Four factor fair use test' discussed on several websites.

England and Raven advised their potential authors that fair use was an entitlement provided only to libraries and not to authors who wished to reproduce a table or illustration, ${ }^{2}$ a restrictive view not supported by Section 107 of the copyright act of the United States or the copyright act of Canada. ${ }^{1,3}$

\section{Copyright Act of Canada Chapter C $-42^{3}$}

Section 29 (page 35) addresses the concept of 'Fair Dealing' as an exception to the copyright act. The sections relevant to this commentary are reproduced exactly ${ }^{3}$ :

"Fair dealing:

29. Fair dealing for the purpose of research or private study does not infringe copyright.

29.1. Fair dealing for the purposes of criticism or review does not infringe copyright if the following are mentioned: (a) the source; and (b) if given in the source, the name of the (i) author, in the case of a work."

The factors used by Canadian courts to determine fair dealing include the length of the excerpt that has been reproduced, the relative importance of the excerpt in relation to the rest of the article, the use made of the work, and the nature of use i.e. criticism, review or summary. ${ }^{4}$

\section{Copyright acts in other countries}

These will not be discussed, although the concept of fair dealing is apparently present in the common law of the Commonwealth of Nations, ${ }^{5}$ including the United Kingdom. ${ }^{6}$

\section{The Conference on Fair Use (CONFU) Report ${ }^{7}$}

The conference brought together copyright owners and users on several occasions, between 1994 and 1998, to create guidelines for fair use of copyrights works by librarians and educators. About a hundred organizations were ultimately represented. The objective was not met because of the "competing interests of the copyright owner and user communities."7

\section{The power of large publishers ${ }^{8,9}$}

In 2007, Dr. Shelley Batts, then a $\mathrm{PhD}$ candidate, was allegedly threatened by lawyers for the journal/publisher after she apparently reproduced a portion of an article from the Journal of the Science of Food and Agriculture (published by Wiley Interscience). ${ }^{8,9}$ One blogger described the act as an assault by a wealthy powerful organization on a scientist that would have a "chilling effect" on science, and behaviour that went against the letter and intent of the law.

\section{Guidelines}

International association of scientific, technical and medical publishers (STM) and the Professional Scholarly and Publishing Division of the Association of American Publishers (PSP) ${ }^{10}$

These associations (STM and PSP) have made explicit recommendations for the reproduction of limited amounts of material from "published journal articles," for the benefit of member publishers (if they are the copyright holders) on the one hand and "researchers and scholars" on the other. With some possible exceptions (such as complex illustrations), permission is not required and a fee not charged for the following: (1) a maximum of two figures (including tables) from a journal article or five figures per journal volume, and (2) single text extracts of less than 100 words or series of text extracts totalling less than 300 words for quotation, in all media and future editions. The purpose must be scholarly comment, non-commercial research or education. Full credit must be given to publishers and authors, and the quotation or excerpt must "never be modified". ${ }^{10}$ These guidelines are in accordance with fair use/dealing. However, no advice is given for the situation in which an author may wish to modify (add or exclude some information, to improve or update earlier data) in the contents of a table or figure, but credit author of prior versions.

\section{Back to the examples}

Most requests for reproduction of an isolated table or figure, scientific or other, would fall within the fair use/dealing law, as mine did. In the examples cited, I would submit that WKHMR violated 'Fair Use' and 'Fair Dealing', while Wiley-Blackwell respected them.

The steps to obtain permission to reproduce a table from one's own article are also tortuous. In another recent experience, the managing editor of the journal in which an article had been previously published, acknowledged that the process seemed "much more complicated than necessary" and intervened on my behalf.

Reproduction of radiological information has been discussed by Stern and Westenberg, ${ }^{11}$ and will not be addressed here.

\section{Why should we promote fair use/fair dealing?}

Much of the advance in knowledge is derivative i.e., we build upon the work of others; how can one claim absolute copyright in such a circumstance? Authors do not get paid for their publications in journals, and rarely if ever for contributions to texts or monographs. Most publish without gain as a motive and with the expectation that their work will be freely available. Publishers do not absorb costs incurred by authors, although presumably they profit from publishing the journals (or monographs) in which the scholarly work is published. Charges are a serious deterrent to reproducing tables or figures. Additionally, paraphrasing tables or crucial portions of text to circumvent the permission process can alter the original meaning. Charges are an insurmountable road block for authors in developing countries. The law rightly suggests that payment is not required for fair use/dealing.

\section{CONCLUSIONS: HOW CAN WE PROMOTE FAIR USE/ DEALING?}

The relationship between publishers and users (authors, educational institutions and other subscribers of journals, purchasers of texts, monographs etc.) is symbiotic. Hence, publishers should be in the forefront of this effort, and enforce fair use/dealing uniformly among their ranks. The STM and PSP guidelines are clear and laudable but voluntary, even for member publishers. ${ }^{10}$ The expenses incurred to maintain a 'permissions team' and staff to handle requests and monitor alleged violations must be considerable, and is ultimately borne by user groups. A 
cost-beneficial approach is in everyone's interest, including the publishers'.

Even if a reproduction falls within fair use/dealing, it is traditional, prudent, collegial and ethical for authors to seek permission to do so, although the law may not require it. The process to apply for permission should be stream-lined, made user-friendly and flexible.

Educational institutions are the custodians of academic freedom and promoters of knowledge. They must blacklist publishers who contravene fair use/fair dealing. The 'publish or perish' philosophy unwittingly created by universities has made us captive to publishers. The impact factor should not be used blindly. Brumback has argued that the impact factor, now apparently under the control of a for-profit company, can be manipulated. ${ }^{12}$ Universities and granting agencies should give the highest ratings to journals that allow open access (without cost to author or user) and those that respect the fair use/fair dealing doctrines.

Editors of journals must unite to clarify and further fair use/dealing. The prerogative of granting reproduction should be restored to authors, and the right enshrined in copyright forms. Creative Commons offers a range of copyright licensing options that are becoming increasingly accepted by copyright owners and users. ${ }^{13}$

Publishing houses have become multi-national and there is increasing international research collaboration. There is urgent need for the principles of fair use and fair dealing to be ratified by all stake-holders uniformly across the globe.

\section{Note}

'Fair use' and 'fair dealing' may be similar lay concepts. However, there may be subtle legal differences in their meaning. Hence, the awkward usage of "fair use/dealing" in portions of the text. Email exchanges pertinent to WKHMR have been shared with the editor.

\section{ACKNOWLEDGMENTS}

The author thanks Miss Maya Seshia and Mrs. Shaila SeshiaGalvin (doctoral students) and Dr. Molly Seshia for suggesting improvements to the manuscript. SSS is very grateful to Monsieur Laurent Carrière of the legal firm Leger Robic Richard, g.p., and patent and agency firm Robic, g.p., Montreal, for helpful discussion. SSS is solely responsible for any errors in interpreting the laws that have been discussed.

\section{REFERENCES}

1. Circular 92. Copyright Law of the United States and Related Laws contained in Title 17 of the United States Code. October 2009. [cited 2010 Apr 14]. Available from: http://www.copyright.gov /title17/circ92.pdf

2. England SL, Raven PB. An interpretation of copyright law. Med Sci Sports Exerc. 1996 Apr; 28(4):401-2

3. Copyright Act Chapter C-42. Published by the Minister of Justice, Government of Canada. Act current to March 25, 2010. Available from: http://laws-lois.justice.gc.ca. [cited 2010 Apr 14].

4. Carrière L. Fair dealing in Canada. [cited 2010 Apr 14]. Available from: http://www.robic.ca/publications/PDF/032E-LC.pdf.

5. Wikipedia. Fair dealing. [cited 2010 Apr 14]. Available from: http://en.wikipedia.org/ wiki/Fair dealing.

6. The British Academy and the Publishers Association. Joint guidelines on copyright and academic research. April 2008. [cited 2010 Apr 14] http://www.publishers.org.uk/en/home/ copyright/copyright_guidelines.

7. Lehman BA. The Conference on Fair Use: final report to the Commissioner on the conclusion of the Conference on Fair Use. September 1998. ISBN 0-9668180-2-4. United States Patent and Trade Mark Office. [cited 2010 Apr 14]. Available from: www.uspto.gov/web/offices/ dcom/olia/confu/indexx.html.

8. Batts S. When Fair Use isn't Fair. [cited 2010 Apr 14]. Available from:http://scienceblogs.com/retrospectacle/2007/04/when_fair _use_isnt_fair_1.php.

9. Chu-Carroll MC. Legal threats (updated): good math, bad math. [cited 2010 Apr 14]. Available from: http://scienceblogs.com/ goodmath/2007/ 04/legal_threats.php.

10. International association of scientific, technical \& medical publishers (STM) and Professional scholarly publishing (PSP). Guidelines for quotation and other academic uses of excerpts from journal articles. February 2008. [cited 2010 May 11]. Available from: ht t p://www.stm-as soc.org/document_library. php?document_portfolio=copyright\&document_type=Guidelines.

11. Stern EJ, Westenberg L. Copyright law and academic Radiology: rights of authors and copyright owners and reproduction of information. AJR Am J Roentgenol. 1995 May;164(5):1083-8.

12. Brumback RA. Worshipping false idols: the impact factor. J Child Neurol. 2008 Apr; 23(4):365-7.

13. Creative Commons. [cited 2010 Apr 14]. Available from: http://creativecommons.org/ about. 